Article

\title{
Low-Voltage and High-Reliability RF MEMS Switch with Combined Electrothermal and Electrostatic Actuation
}

\author{
Yong Zhu ${ }^{1, *(D)}$ and Jitendra Pal ${ }^{2}$ (D) \\ 1 Queensland Micro and Nanotechnology Centre, Griffith University, Nathan, QLD 4111, Australia \\ 2 Wispry Inc., Irvine, CA 92618, USA; jpiitr84@gmail.com \\ * Correspondence: y.zhu@griffith.edu.au
}

Citation: Zhu, Y.; Pal, J. Low-Voltage and High-Reliability RF MEMS Switch with Combined Electrothermal and Electrostatic Actuation. Micromachines 2021, 12, 1237. https://doi.org/ 10.3390/mi12101237

Academic Editor: Joshua En-yuan Lee

Received: 12 September 2021

Accepted: 8 October 2021

Published: 12 October 2021

Publisher's Note: MDPI stays neutral with regard to jurisdictional claims in published maps and institutional affiliations.

Copyright: (c) 2021 by the authors. Licensee MDPI, Basel, Switzerland. This article is an open access article distributed under the terms and conditions of the Creative Commons Attribution (CC BY) license (https:/ / creativecommons.org/licenses/by/ $4.0 /)$.

\begin{abstract}
In this paper, we report a novel laterally actuated Radio Frequency (RF) Microelectromechanical Systems (MEMS) switch, which is based on a combination of electrothermal actuation and electrostatic latching hold. The switch takes the advantages of both actuation mechanisms: large actuation force, low actuation voltage, and high reliability of the thermal actuation for initial movement; and low power consumption of the electrostatic actuation for holding the switch in position in ON state. The switch with an initial switch gap of $7 \mu \mathrm{m}$ has an electrothermal actuation voltage of $7 \mathrm{~V}$ and an electrostatic holding voltage of $21 \mathrm{~V}$. The switch achieves superior RF performances: the measured insertion loss is $-0.73 \mathrm{~dB}$ at $6 \mathrm{GHz}$, whereas the isolation is $-46 \mathrm{~dB}$ at $6 \mathrm{GHz}$. In addition, the switch shows high reliability and power handling capability: the switch can operate up to 10 million cycles without failure with $1 \mathrm{~W}$ power applied to its signal line.
\end{abstract}

Keywords: microelectromechanical systems (MEMS); radio frequency (RF); switch; electrothermal actuation; electrostatic actuation; insertion loss; isolation

\section{Introduction}

The increasing demand for high-performance, low-cost, and miniaturized wireless communication systems has driven the rapid development of novel devices for radio frequency $(\mathrm{RF})$, microwave, and millimeter-wave circuits and systems. RF switches are essential devices to handle RF signal in these systems. Conventionally, RF switching has been done using semiconductor devices such as positive-intrinsic-negative (PIN) diodes and field-effect transistors (FETs) [1-3]. However, these semiconductor switches inherently suffer high losses at high frequencies in $\mathrm{GHz}$ range. Many researchers have attempted to investigate potential RF switching devices which are compact, linear, and power efficient. RF microelectromechanical systems (MEMS) are one of the potential candidates which have reformed the RF systems by realization of high-performance devices and components. For instance, RF MEMS switches have superior electrical performance compared to the traditional solid-state solutions, e.g., higher linearity, higher isolation, lower insertion loss, smaller size, and lower cost $[4,5]$.

To achieve high isolation, large separation gap in OFF state is needed in RF transmission line. Currently, electrothermal and electrostatic actuators are widely used to generate large separation displacement in MEMS switches. Electrothermally actuated devices have simple fabrication processes, require lower actuation voltage, and are suitable for an application which demands higher contact force [6,7]. However, electrothermal actuation consumes high power which limits it from some applications where devices need to maintain $\mathrm{ON}$ position for a significant period of time [8]. By contrast, electrostatic actuated devices consume nearly zero low power as no DC current is needed during the actuation process. However, electrostatic based devices are limited by the trade-off between operating voltages and mechanical properties of the device [9]. For example, the operating voltage required is limited by the available voltage on the device in the whole RF system, which may be typically low (e.g., $5 \mathrm{~V}$ ). However, high operating voltage, typically more 
than $50 \mathrm{~V}$ is required to reduce the parasitic load of the RF signal line, avoid a self-latching, and have a large mechanical separation between input and output ports.

In addition, RF MEMS switches mainly adopt metal-to-metal contact and capacitive coupling for the switching operations. The metal-to-metal contact requires good ohmic contact between two metal electrodes, whereas capacitive coupling switches have a thin dielectric film and an air gap between two metal electrodes. However, the above-mentioned contact topologies both suffer long-term reliability issues, thereby limiting their practical use in commercial applications [10,11]. For example, the issues include the dielectric charging due to large contact areas in capacitive coupling switch [12], and the stiction due to low restoring spring force in the metal contacting switches [13].

To solve the above issues, we propose a new design of MEMS switches, combining the unique characteristics of electrothermal and electrostatic actuators. This can avoid the high-power consumption issue in an electrothermal actuator as well as high-voltage issue in an electrostatic actuator [14-17]. Previously, a similar concept has been used in [18-21]: these designs utilize electrothermal actuators to bring the switch contacts near to signal lines and then hold the switches in ON state with electrostatic actuation. In another attempt, the switches are also integrated with electrostatic and electromagnetic actuation to achieve similar advantages [22,23]. However, they are all vertically actuated (out-of-plane) which require special fabrication process, thereby making the overall process complicated and the device less reliable. Compared to those vertically actuated MEMS switches, the laterally actuated MEMS switches have the advantages of in-plane design flexibility, high mechanical stability and reliability, and simple process. In addition, the actuators and the RF structures can be fabricated in a single lithographic step which dramatically reduces the fabrication cost and improves the production yield. Besides, it is easy to get a large separation, large contact area, and restoring force under a low voltage.

In this paper, we report a lateral actuated RF MEMS switch that employs a two-step switching operation: a V-shaped electrothermal actuator moves the switch contacts to touch the separated RF signal lines (close the switch); and then the switch remains in the ON state using electrostatic latching mechanism. The fabricated device avoids the constant power consumption requirement for electrothermal actuator and the high voltage requirement for electrostatic actuator when large gaps are required. Hence, power is consumed only during the electrothermal actuation for a short period and the switch consumes almost zero power by electrostatic latching in the holding period.

This paper is organized as follows. In Section 2, we demonstrate the design concept and operation of the proposed MEMS switch. This section also discusses simulation results using Intellisuite and the fabrication process for the proposed design. Section 3 then presents the measurement results and discussion. Finally, conclusion is presented in Section 4.

\section{Materials and Methods}

\subsection{Design}

The schematic diagram of the proposed design is shown in Figure 1. The switch consists of five main parts including Co-planar waveguide (CPW), fixed electrode, movable electrode (slider), V-shaped electrothermal actuator, and electrostatic holding electrodes. The movable slider (electrode) changes the switch states between ON and OFF by connecting and disconnecting contact tips in the separated RF signal line. A V-shaped electrothermal actuator is used to drive the movable electrode to close the switch, and then the electrostatic holding electrodes hold the movable electrode in contact position of ON state. The design has the combined advantages of low actuation voltage from electrothermal actuator and low power consumption in $\mathrm{ON}$ state due to electrostatic latching. In addition, the switch offers large initial gap of $7 \mu \mathrm{m}$ between signal line and movable electrodes, which provides high isolation benefit that is difficult to achieve in electrostatic actuation. To increase reliability and power-handling capability, the switch is designed with high spring constant which restricts the switch from stiction issue and self-actuation issue. Moreover, 
the air gap between the slider and the actuator prevents the heat transferring from actuator to RF signal line.

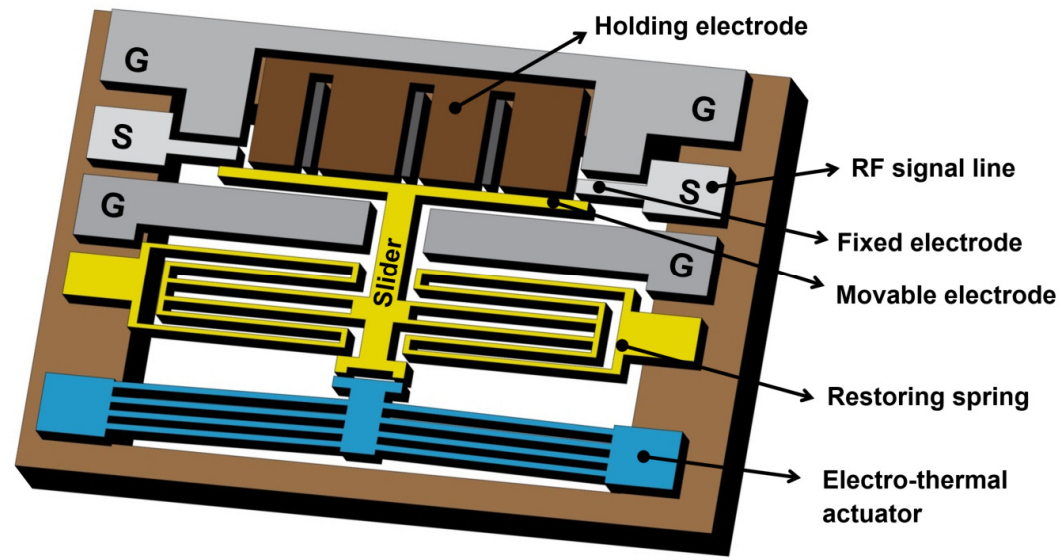

Figure 1. Schematic diagram of the proposed microelectromechanical systems (MEMS) switch design with combined electrothermal actuation and electrostatic hold.

The switching mechanism and steps of proposed design are shown in Figure 2. During switching states, the main acting forces are: (1) thermal expansion force, (2) spring force, and (3) electrostatic force. In the initial step (see Figure 2a), a large air gap of $7 \mu \mathrm{m}$ exists between the RF signal line and the switching electrode (slider) to make the switch in OFF state with good isolation. Then electrical current follows through the V-shaped electrothermal actuator, thermal expansion force pushes the slider to close the air gap and contact with the transmission line, shifting the switch into ON state (see Figure 2b). Next, the voltage applied to the holding electrode generates electrostatic force between fixed electrode and movable electrode. The electrostatic force is sufficiently high to hold the switch in ON state, so the applied current in the thermal actuator can be removed to reduce the power consumption (see Figure 2c). The switch can finally return to its initial position (OFF state) by the spring's restoring force when the applied voltage on holding electrode is removed. In the whole operation, the electrostatic force is only operated during the electrostatic latching when the gap between fixed electrode and moving electrode is very small $(500 \mathrm{~nm})$, therefore the switch requires low operating voltage. In addition, electro-thermal force is only needed for a short period during switching states to move the movable electrode to touch the fixed electrode, thus the ON state does not consume power. Therefore, the proposed design can be implemented in the applications where both low actuation voltage and low power consumption are required.

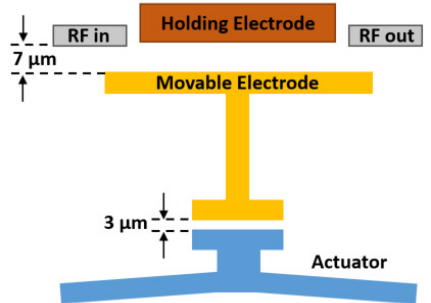

(a)

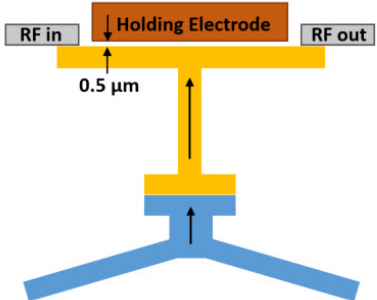

(b)

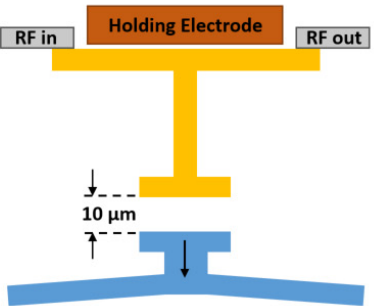

(c)

Figure 2. Switching mechanism and steps: (a) initial OFF state; (b) intermediate state with actuation voltage applied to electrothermal actuator to close the switch; (c) ON state latched by electrostatic force from the holding electrode. 


\subsection{Modeling and Simulation}

To analyse the performance and optimize the proposed design, finite element method (FEM) simulation is conducted using IntelliSuite's Coupled Thermoelectromechanical Solver (IntelliSense Inc., Lynnfield, MA, USA). The material properties and optimized dimensions of the switch are summarized in Table 1. The initial state of the switch is OFF because the movable beam does not contact the signal line (with an initial air gap of $7 \mu \mathrm{m}$ ). When electric current flows through the V-shaped beams, the electrothermal actuator generates movement due to the thermal expansion of its material. As a result, the movable electrode moves upward and touches the broken signal lines (see Figure 2b). Figure 3 shows the simulated corresponding curve between maximum temperature and various applied actuation voltages from 1 to $7 \mathrm{~V}$. The results show that the maximum temperature in the thermal actuator is $475{ }^{\circ} \mathrm{C}$, which is well below the melting point of silicon. To provide thermal and electrical isolations from the silicon substrate, the device is trenched completely underneath the movable structures. Figure 3 also plots the simulated corresponding curve of displacement with applied voltage. The switch provides large displacement with much lower voltage compared with electrostatic actuation counterparts [9].

Table 1. Material properties of the bulk silicon used in the switch and the optimized device dimensions.

\begin{tabular}{|c|c|c|c|}
\hline Properties and Dimensions & Name & Value & Unit \\
\hline \multirow{3}{*}{ Mechanical Properties } & Young's modulus & 170 & $\mathrm{GPa}$ \\
\hline & Poisson's ratio & 0.28 & - \\
\hline & Density & 2.3 & $\mathrm{~g} / \mathrm{cm}^{3}$ \\
\hline \multirow{2}{*}{ Thermal Properties } & Thermal conductivity & 1.46 & $\mathrm{~W} / \mathrm{cm} \cdot \mathrm{K}$ \\
\hline & Thermal expansion coefficient & $2.7 \times 10^{-6}$ & $\mathrm{~K}^{-1}$ \\
\hline Electrical Properties & Electrical resistivity & 0.013 & $\mathrm{ohm} \cdot \mathrm{cm}$ \\
\hline \multirow{11}{*}{$\begin{array}{c}\text { Geometry Dimensions of } \\
\text { the Designed Switch } \\
\text { Structures }\end{array}$} & Length of V-shaped actuator beams (each side) & 400 & $\mu \mathrm{m}$ \\
\hline & Width of V-shaped actuator beams & 10 & $\mu \mathrm{m}$ \\
\hline & Angle of V-shaped actuator beams & 0.6 & $\circ$ \\
\hline & Number of V-shaped actuator beams (each side) & 6 & - \\
\hline & Length of Suspension spring (each side) & 470 & $\mu \mathrm{m}$ \\
\hline & Width of Suspension spring (each side) & 5 & $\mu \mathrm{m}$ \\
\hline & Device thickness & 25 & $\mu \mathrm{m}$ \\
\hline & Initial gap between switching electrodes, $d$ & 7 & $\mu \mathrm{m}$ \\
\hline & Holding electrode gap, $g$ & 0.5 & $\mu \mathrm{m}$ \\
\hline & Holding electrode overlap area, $A$ & $830 \times 25$ & $\mu \mathrm{m}^{2}$ \\
\hline & Switch contact area (each side) & $6.5 \times 25$ & $\mu \mathrm{m}^{2}$ \\
\hline
\end{tabular}

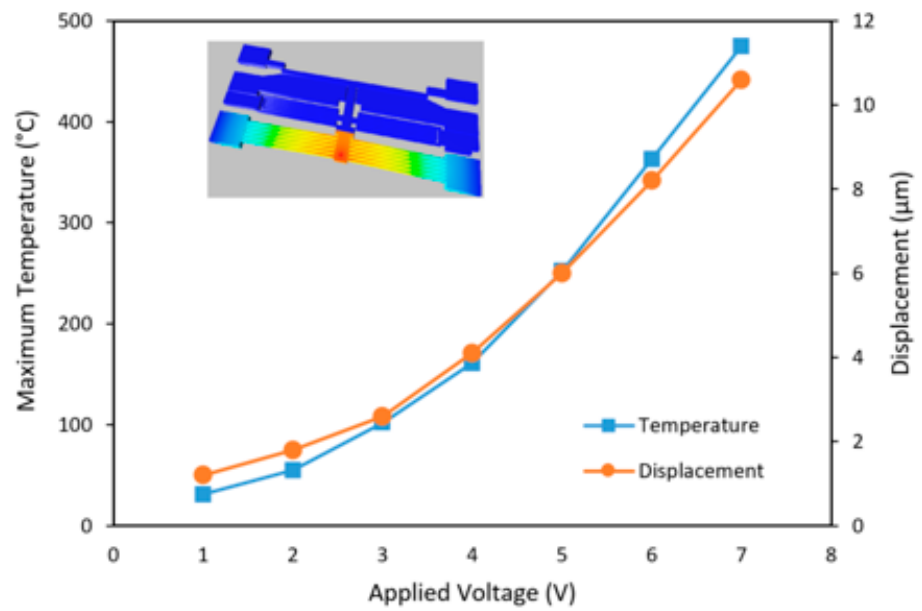

Figure 3. The simulated maximum temperature and displacement of the electrothermal actuator with various applied actuation voltages. 
When the movable beam touches the broken signal lines, a holding voltage $V$ is applied between fixed electrode and movable beam to hold the movable electrode in position (see Figure 2c). Then the electric current in the V-shaped actuator is removed to reduce the power consumption. The electrostatic holding force $F_{\text {hold }}$ generated by the holding electrode can be estimated by

$$
F_{\text {hold }}=\frac{\varepsilon A V^{2}}{2 \mathrm{~g}^{2}}
$$

where $\varepsilon$ is the dielectric constant of air; $A$ and $g$ are the overlap area and final gap between the holding electrode and movable electrode, respectively. When the electrostatic holding force $F_{\text {hold }}$ and the restoring force of the suspension spring are equal, the holding voltage can be defined as

$$
V_{\text {hold }}=g \sqrt{\frac{2 k d}{\varepsilon A}}
$$

where $d$ is the initial gap between switching electrodes and $k$ is the spring constant of the suspension beam. As Equation (2) implicated, a low holding voltage can be obtained by manipulating the parameters: $k, d, g$, and $A$. In our design, the spring constant $k$ is $19.81 \mathrm{~N} / \mathrm{m}$ (simulated using Intellisuite), initial gap $d$ is $7 \mu \mathrm{m}$, overlap area $A$ is $830 \times 25 \mu \mathrm{m}^{2}$, and final gap $g$ is $0.5 \mu \mathrm{m}$. According to Equation (2), the required holding voltage is $19.4 \mathrm{~V}$. The holding voltage can be reduced further by increasing the overlap area or decreasing the spring constant. However, larger overlap area will increase the overall device size, while smaller spring constant will make the device less robust to mechanical shock. As shown in Equation (2), initial gap $g$ is outside of the square root operation, which means it is more significant in changing $V_{\text {hold }}$ values compared to other parameters. Figure 4 plots the corresponding curve between required holding voltage $V_{\text {hold }}$ and initial gap $g$. When the initial gap varies from $1 \mu \mathrm{m}$ to $10 \mu \mathrm{m}$, the required holding voltage changes from $7.34 \mathrm{~V}$ to $23.22 \mathrm{~V}$, which is fairly low in comparison with typical actuation voltage $(\sim 100 \mathrm{~V})$ in electrostatic actuation.

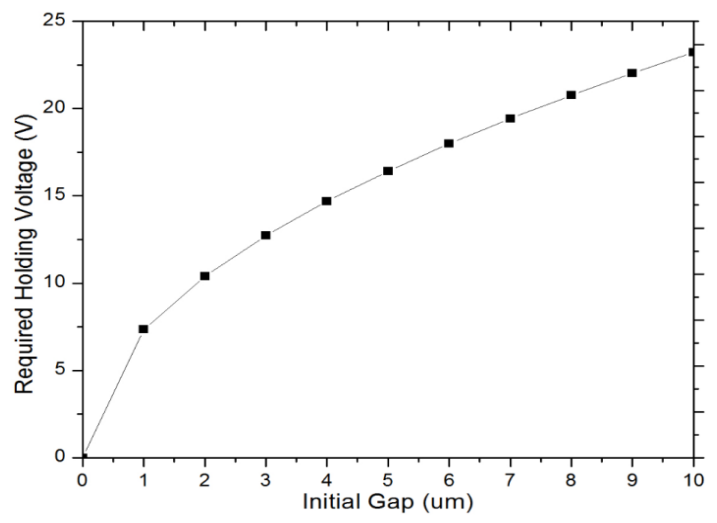

Figure 4. Required electrostatic holding voltages versus various initial gaps between switching electrodes.

To investigate and optimize the RF performance of the proposed switch, the finite integration technology has been utilized in CST Microwave Studio. The coplanar waveguide (CPW) transmission line is set as gap/width/gap (G/W/G) of 55/100/55 $\mu$ m for a $50 \Omega$ impedance. The simulated results show very low insertion loss of $-0.58 \mathrm{~dB}$ in $\mathrm{ON}$ state and very high isolation of $-43.47 \mathrm{~dB}$ in OFF state at $6 \mathrm{GHz}$, as shown in Figure 5. 


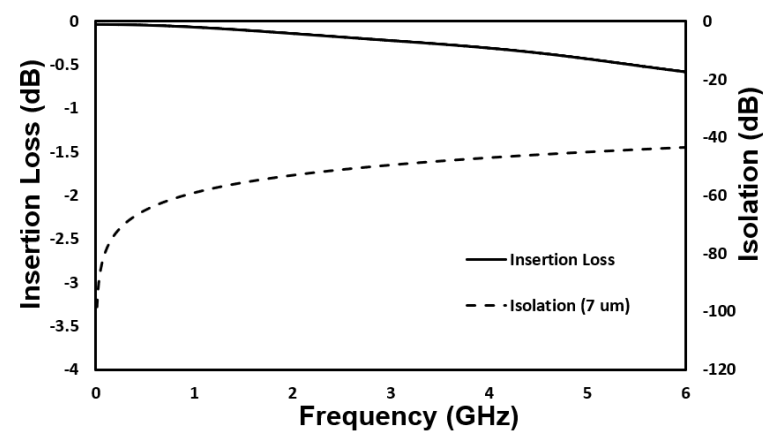

Figure 5. Simulated radio frequency (RF) performances of proposed switch in ON and OFF states.

\subsection{Fabrication}

The proposed design was fabricated using a commercially available SOIMUMPS process [24]. The process starts with a silicon-on-insulator (SOI) wafer consisting of a $25 \mu \mathrm{m}$ silicon layer, a $2 \mu \mathrm{m}$ oxide layer, and a $400 \mu \mathrm{m}$ substrate layer as shown in Figure 6 a. To define the mechanical structure, the top silicon layer is lithographically patterned, and deep reactive ion etched (DIRE) (see Figure 6b). Next, trenches are made by selectively backside etching the wafer through the substrate layer (see Figure 6c). The advantages with these trenches include releasing the movable structures in the top silicon layer, and reducing the substrate parasitics, thereby improving the RF performances. In addition, the SOIMUMPs offers two metal layers: (1) the pad metal layer which consists of a $20 \mathrm{~nm}$ chrome and $500 \mathrm{~nm}$ of gold for the electrical connection; and (2) the blanket metal layer consisting of $600 \mathrm{~nm} \mathrm{Au}$ and $50 \mathrm{~nm} \mathrm{Cr}$. The blanket metal layer partially overcoated on the silicon structure, which can reduce the RF signal loss in the signal line as well as reduce the switch contact resistance. The pad metal layer is patterned through a lift-off process whereas the blanket metal layer is deposited using a shadow mask technique to reduce the contact resistance (see Figure $6 \mathrm{~d}$ ). To further reduce the contact resistance, a $1 \mu \mathrm{m} \mathrm{Cu}$ is over-coated on the top and sidewall of the switching area by sputtering process [25-27]. Figures 6 and 7 illustrate the fabrication process flow with the key steps and SEM image of the fabricated switch, respectively.

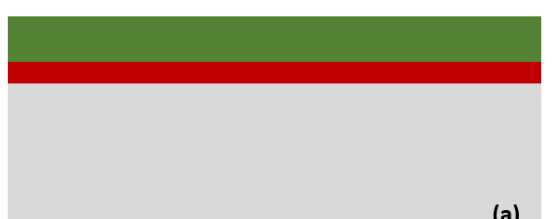

(a)

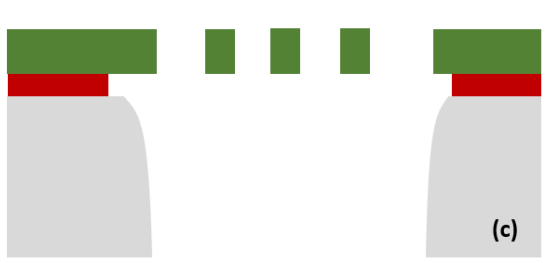

Silicon substrate
Silicon structure

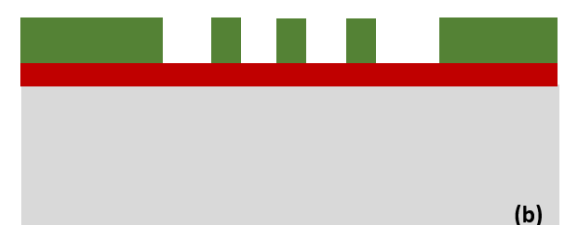

(b)

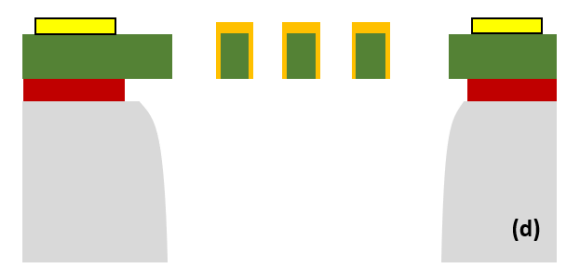

(d)

Figure 6. Fabrication process flow including four key steps: (a) starting SOI wafer, (b) Si structure patterning by deep reactive ion etched (DRIE), (c) Structure releasing by backside DRIE dry etching and wet etching, and (d) Metal layers deposition for connection and overcoating. 


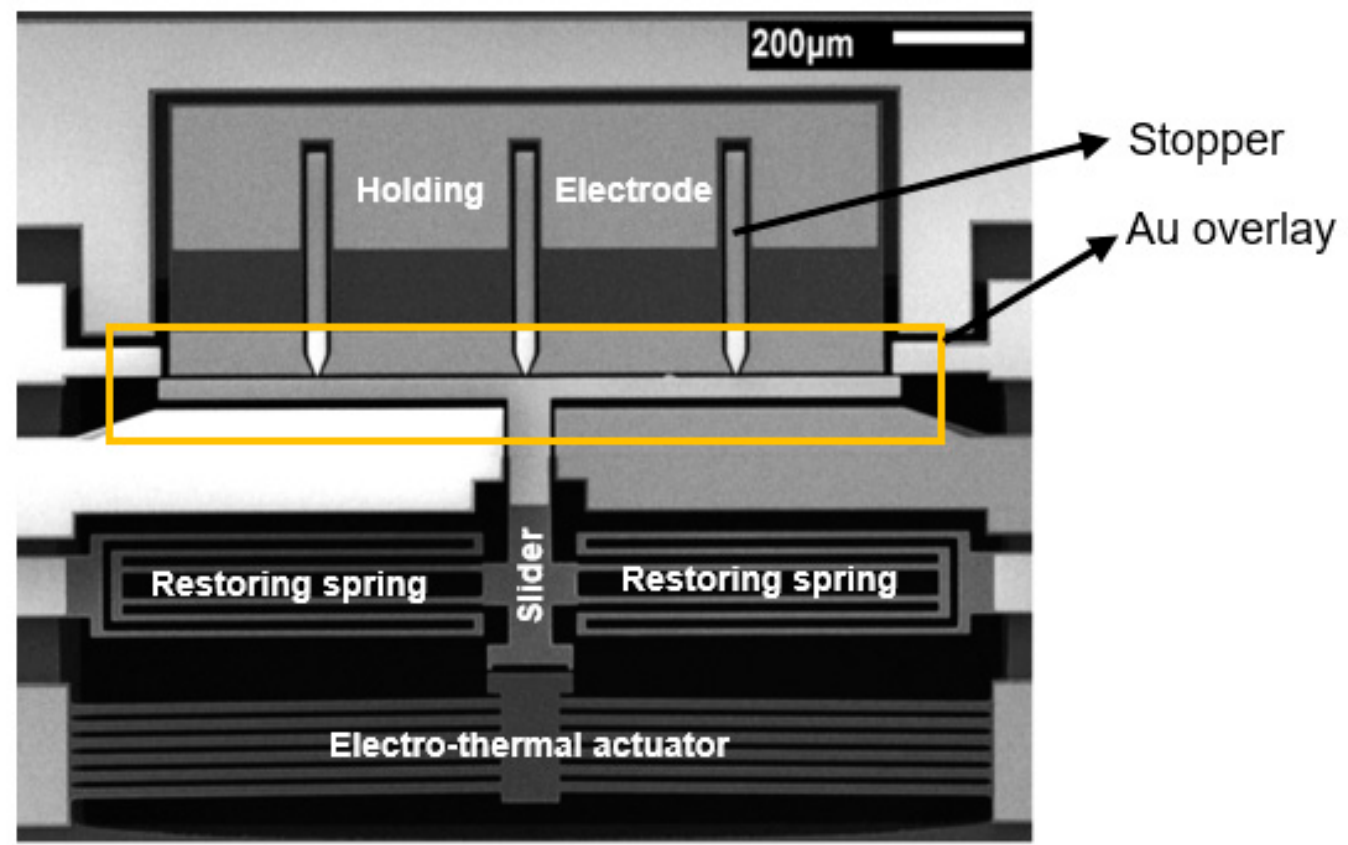

Figure 7. Scanning Electron Microscopy (SEM) photo of the fabricated switch. Au overlay is added to reduce the contact resistance and RF signal loss. Three stoppers ensure no contact and short circuit between movable electrode and holding electrode.

\section{Measurements and Discussion}

\subsection{Direct Current (DC) and Transient Measurements}

To characterize the actuation behaviour, the direct current (DC) electromechanical response measurement was implemented. First, we measured the current as a function of applied voltage for the actuator and results are shown in Figure 8a. Approximated linear response has been obtained with an actuator resistance of $178.6 \Omega$ and a power consumption of $273 \mathrm{~mW}$ at the actuation voltage of $7 \mathrm{~V}$. Figure $8 \mathrm{~b}$ plots the curve of displacement with varying applied actuation voltage. As expected, the displacement increases with the increase in voltage and the measured results match the simulation results well. To reduce the thermal conduction to the substrate, air trench was made underneath the actuator (see Figure 6). As a result, the improved electrothermal actuation efficiency helped the actuator achieve large displacement of $10 \mu \mathrm{m}$ under an actuation voltage of $7 \mathrm{~V}$, as shown in Figure $8 \mathrm{~b}$. It should be noted that a total of $10 \mu \mathrm{m}$ actuation displacement is needed to close the switch, which includes $3 \mu \mathrm{m}$ gap of actuator/movable electrode and $7 \mu \mathrm{m}$ gap of holding electrode/movable electrode, as shown in Figure $2 \mathrm{a}-\mathrm{c}$.

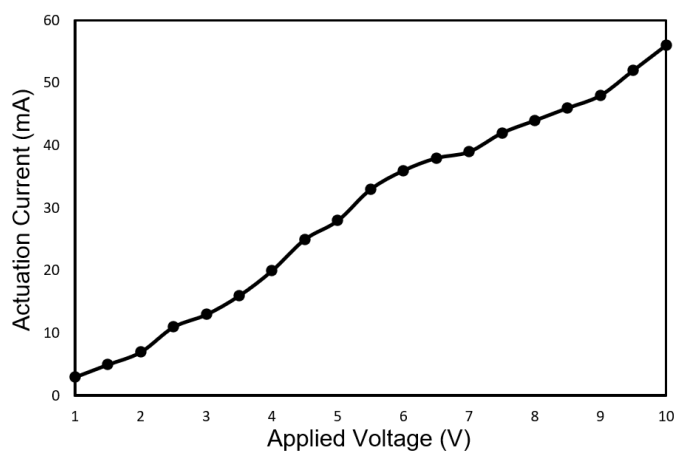

(a)

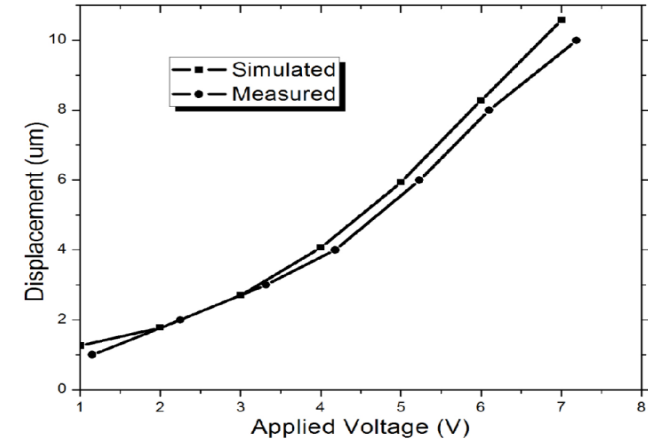

(b)

Figure 8. (a) Measured I-V characteristics of the fabricated V-shaped electrothermal actuator. (b) Comparison between simulation and measured displacements vs. applied actuation voltages. 
Figure 9 illustrates the relationship between contact resistance and applied holding voltage after the switch is closed. The testing result showed that the fabricated switch requires a minimum holding voltage of $21 \mathrm{~V}$ for the switch with initial gap $7 \mu \mathrm{m}$, which matches well with the calculated results of $19.4 \mathrm{~V}$ using Equation (2). The small discrepancy is believed to be due to the fabrication process uncertainties. The holding voltage is applied through a DC voltage source and the switch contact resistance is continuously observed with a digital multimeter. When an applied holding voltage of $21 \mathrm{~V}$ is applied between movable and fixed electrodes, the digital multimeter shows a contact resistance of $1.81 \Omega$. When the applied holding voltage increases from $21 \mathrm{~V}$ to $35 \mathrm{~V}$, the contact resistance reduces to $1.51 \Omega$. This is because the contact force increases with the increase of the applied holding voltage as shown as the simulated electrostatic contact force results in Figure 9. The contact pressure was firstly simulated at various applied voltages using Intellisuite software. Then the contact force was calculated by multiplying contact pressure with the contact area.

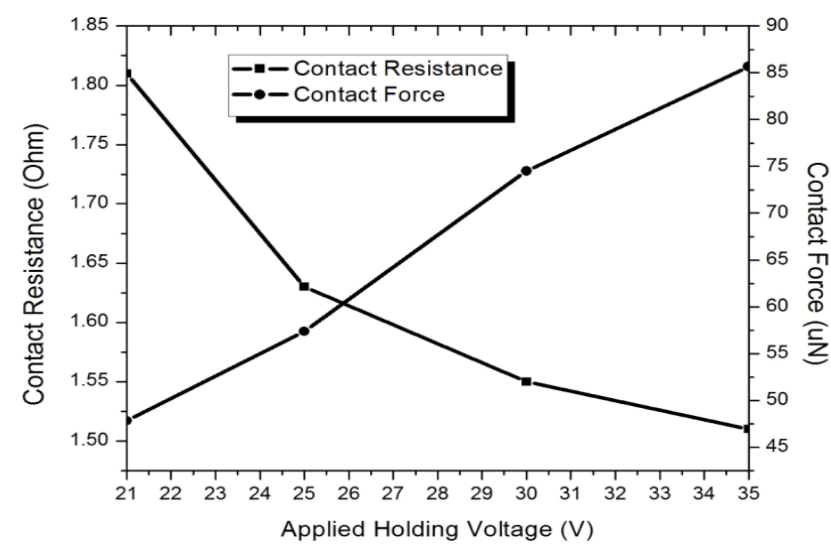

Figure 9. Changes in measured contact resistance and simulated contact force with various applied holding voltages.

Figure 10 illustrates the measurement set-up schematic for measuring the switching times. As the switching drive signal, a $1 \mathrm{~Hz}$ square wave voltage signal (5 Vpp and 50\% duty cycle) is supplied by a function generator. A power MOSFET is used to separate the input control signal from the switch driving voltage signal. The driving voltage is supplied with a constant power supply of $1.5 \mathrm{~V}$. One port of switch is grounded and the other port is connected to an oscilloscope to monitor the transient switching times. Figure 11 plots the measured switching times of the fabricated switch. The switch has shown a response time of $70 \mathrm{~ms}$ for the transition from open state to close state, and a releasing time of $4.12 \mathrm{~ms}$ for the transition from close state to open state. The measured response time is much longer than the releasing time. This is due to the fact that the movable electrode needs to travel a total distance of $10 \mu \mathrm{m}$ before contacting the broken signal line, whereas the disconnection of the switch only needs to separate the movable beam from signal lines by removing the applied drive voltage. It should be noted that the switching speed of the electrothermal actuator is slower compared to that of its electrostatic counterparts. The reason is that electrothermal actuator generates its movement through Joule heating effect, which is inherently slower than electrostatic effect. 


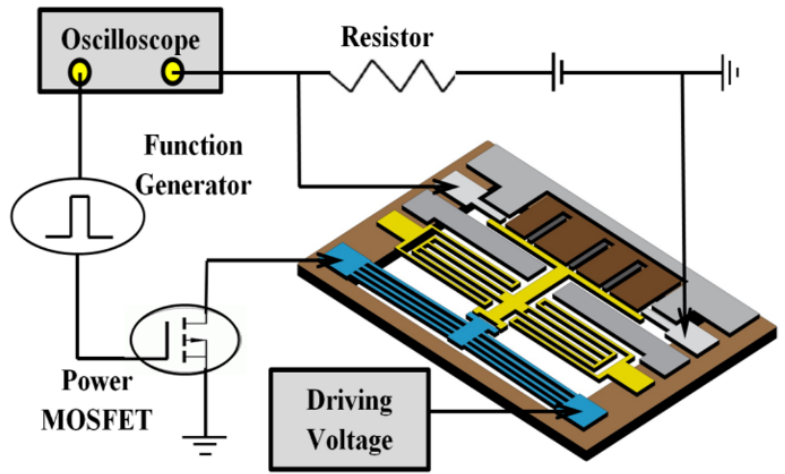

Figure 10. The setup schematic for measuring switching times.

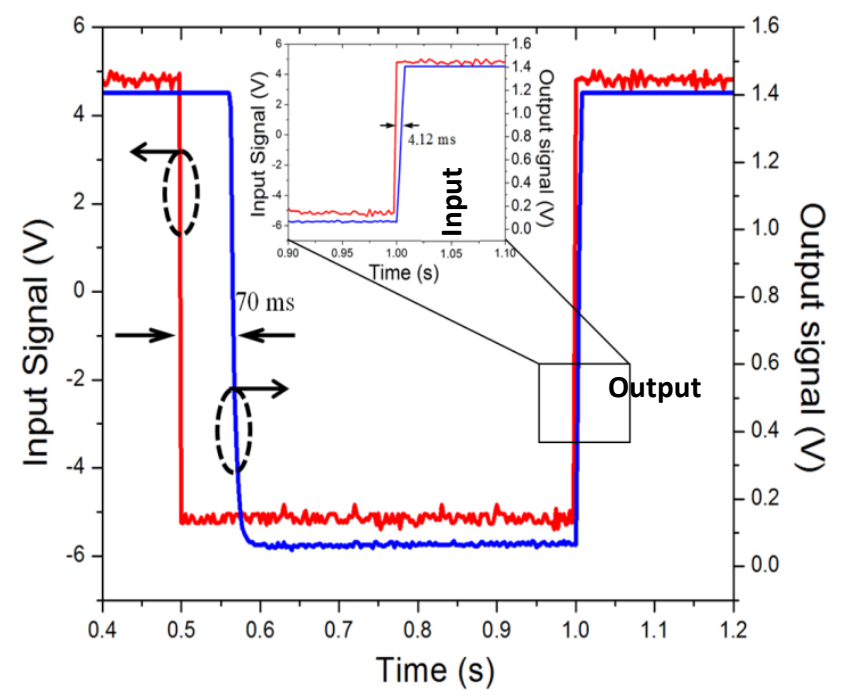

Figure 11. The measured transient switching waveforms of the fabricated switch.

\subsection{RF Characteristics}

The RF performance of the fabricated MEMS switch is characterized using a RF Vector Network Analyzer (FieldFox ${ }^{\mathrm{TM}}$ N9923A, Keysight, Santa Rosa, CA, USA) with ground-signal-ground (GSG) coplanar probes. The system is calibrated using the standard short-open-load-through (SOLT) on-wafer technique. The S-parameters of the input and output ports are extracted using the Vector Network Analyzer. In the measurement setup, input, and output ports of the CPW are connected with the network analyser, while the actuation electrodes are connected with the DC voltage source. When a voltage is applied to the fabricated switch for actuation, the $S$ parameter is measured through input and output ports as shown in Figure 12. In OFF state, the performance of the switch is represented by isolation. The measured isolation is better than $-46 \mathrm{~dB}$ at $6 \mathrm{GHz}$. The high isolation for the fabricated switch is achieved due to large initial gap of $7 \mu \mathrm{m}$ between signal line and the movable electrode. The measured insertion loss in ON state has a maximum value of $-0.73 \mathrm{~dB}$ at $6 \mathrm{GHz}$. The insertion loss includes the losses due to the contact resistive loss, long CPW lines loss and radiation loss due to discontinuity in CPW structure [25]. The RF characteristics of fabricated switch are well matched with simulation results. The small discrepancy between the simulation and measurement results is believed to be caused by fabrication process uncertainties. 


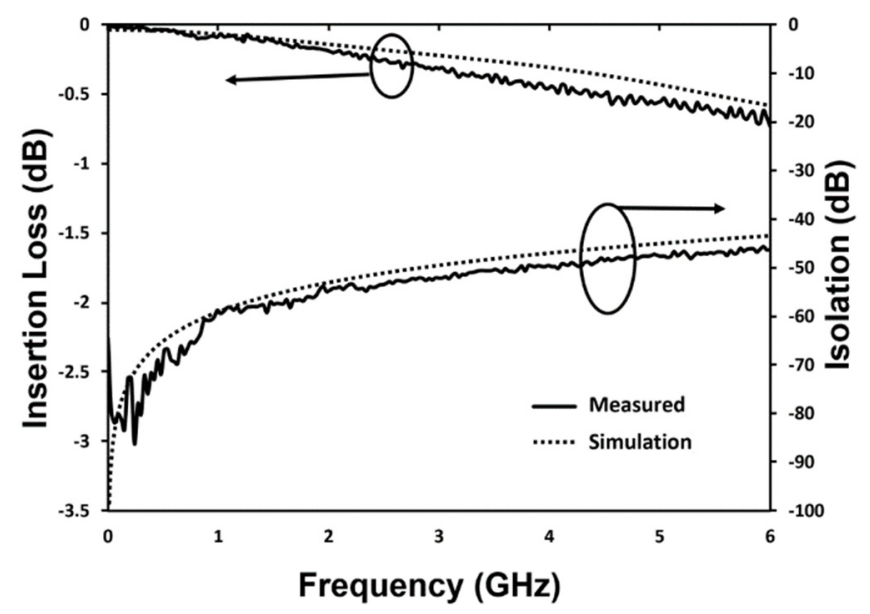

Figure 12. Comparison between the measured and simulated RF performances (Insertion Loss and Isolation) of the fabricated switch.

\subsection{Reliabilty Test}

In MEMS switches, the limitations on lifetime come mainly from hot switching rather than cold switching. The electrostatically actuated switch generally suffers from the mechanism of self-switching and RF latching. In contrast, the electrothermally actuated switches suffer mainly from micro-welding between the contacts. Our electrothermal switch is expected to be independent from these issues because of their high mechanical restoring force. As a result, the main limitations come from the RF current and contact degradation.

In this paper, the hot switching test is done under high RF power. Figure 13 illustrates the measurement setup to measure the RF power handling capability of fabricated switch. To estimate the self-actuation power, an input power signal of $1 \mathrm{~W}$ is applied to the fabricated device which is generated by signal generator and power amplifier. The switch does not show any self-actuation phenomenon when a power of $1 \mathrm{~W}$ is applied, therefore electrostatic force generated by RF voltage between signal lines and movable beam is negligible. To observe micro-welding phenomenon through contact, RF signals at $500 \mathrm{MHz}$ with powers of $1 \mathrm{~W}$ is applied to contacts. The result shows that the switch can handle up to 10 million cycles when a power level of $1 \mathrm{~W}$ is applied to the switch. The test was stopped after 10 million cycles not due to switch failure.

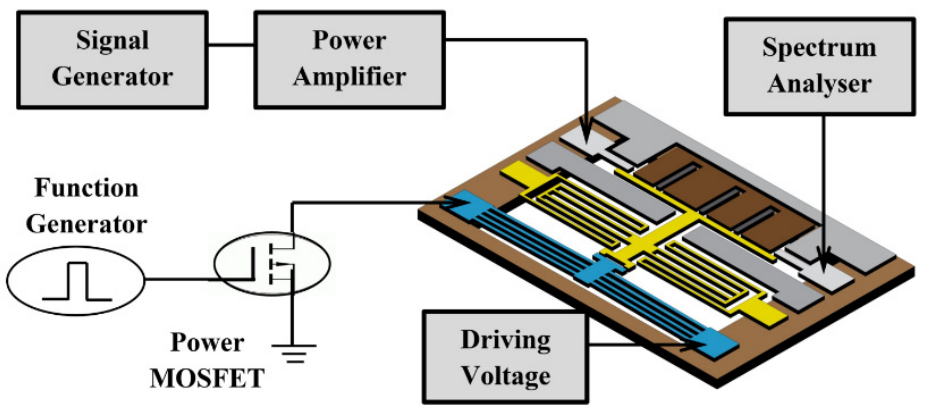

Figure 13. The test setup schematic for measuring RF power handling capability of the fabricated switch.

The contact reliability of the fabricated switch in terms of switching cycles under high voltage is also investigated [28]. The test is conducted in air ambient and hot switching condition with high applied voltage from a dc power supply across a resistive load. The applied voltage is continuously increased in steps of $1 \mathrm{~V}$ until the contact survives. The fabricated switch can handle hot switching up to $35 \mathrm{~V}$ and $0.2 \mathrm{~A}$ across a $100 \Omega$ resistor as shown in Figure 14. When voltage is further increased, the switch failed in open state and contact resistance jumps to several mega-ohms. The mechanisms of failure include 
deterioration of contact surface and deformation of silicon beams. The other possibility of switch failure could be airborne contamination as the measurement was conducted under atmospheric conditions without hermetic packaging. The reliability of the switch can be improved by using hard materials such as Platinum $(\mathrm{Pt})$ and Ruthenium $(\mathrm{Ru})$ instead of commonly used Au-to-Au contact [29-31]. Another way to increase the power handling capability is to reduce the current through each contact by implementing multiple contacts in the switch [32-34]. In addition, hermetic packaging can also improve the switch reliability for its protection from humidity and contamination.

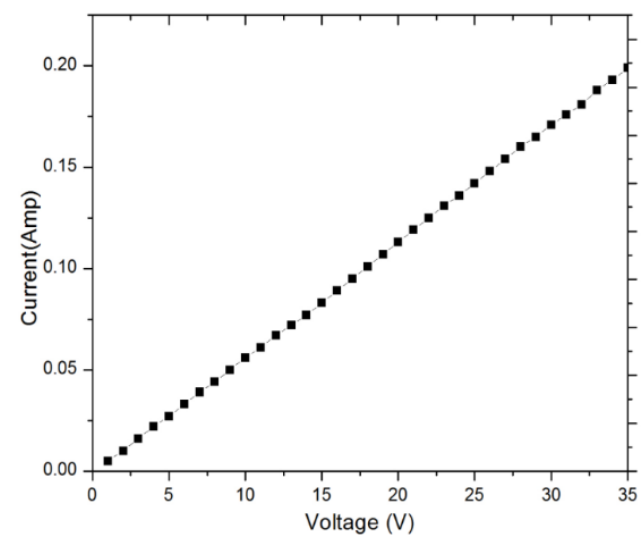

Figure 14. Voltage versus current in hot switching test over a $100 \Omega$ resistor.

\section{Conclusions}

In this paper, a novel low-voltage and high-reliability switch actuated with the combination of electrostatic and electrothermal actuation is designed, fabricated, and characterized. By using the combined actuation mechanisms, the switch can achieve a low actuation voltage of $7 \mathrm{~V}$ and a low holding voltage of $21 \mathrm{~V}$. The proposed switch exhibits excellent RF performances in terms of insertion loss and isolation. The measured insertion loss and isolation is $-0.7 \mathrm{~dB}$ and $-46 \mathrm{~dB}$ at $6 \mathrm{GHz}$, respectively. The switch did not show any self-actuation phenomenon with the input power of $1 \mathrm{~W}$. The hot switching results indicate that the switch can handle high power up to $1 \mathrm{~W}$ for 10 million cycles without failure. Although the switching time of the proposed fabricated switch is longer compared to electrostatic actuation, the fabricated switch can be used in the application where longer switching time can be affordable such as multiband receiver band selection networks, redundancy networks, etc. It is noted that this paper is focused on a novel concept for low voltage and low power consumption, and robustness tests will be investigated in future studies.

Author Contributions: Conceptualization, Y.Z.; Data curation, Y.Z. and J.P.; Formal analysis, Y.Z. and J.P.; Funding acquisition, Y.Z.; Investigation, Y.Z. and J.P.; Methodology, Y.Z.; Project administration, Y.Z.; Software, J.P.; Supervision, Y.Z.; Validation, J.P.; Writing—original draft, J.P.; Writing—review \& editing, Y.Z. All authors have read and agreed to the published version of the manuscript.

Funding: This research received no external funding.

Conflicts of Interest: The authors declare no conflict of interest.

\section{References}

1. Chen, W.H.; Sun, J.W.; Wang, X.; Feng, Z.H.; Chen, F.L.; Furuya, Y.; Kuramoto, A. A Novel Planar Switched Parasitic Array Antenna With Steered Conical Pattern. IEEE Trans. Antennas Propag. 2007, 55, 1883-1887. [CrossRef]

2. Kobayashi, K.; Tran, L.; Oki, A.; Streit, D. A 50 MHz-30 GHz broadband co-planar waveguide SPDT PIN diode switch with 45-dB isolation. IEEE Microw. Guided Wave Lett. 1995, 5, 56-58. [CrossRef]

3. Teeter, D.; Wohlert, R.; Cole, B.; Jackson, G.; Tong, E.; Saledas, P.; Adlerstein, M.; Schindler, M.; Shanfield, S.; Div, R. Ka-band GaAs HBT PIN diode switches and phase shifters. In 1994 IEEE MTT-S International Microwave Symposium Digest; IEEE: Piscataway, NJ USA, 1994; pp. 451-454 
4. Majumdar, S.; McGruer, N.E.; Adams, G.G.; Zavracky, P.M.; Morrison, R.H.; Krim, J. Study of contacts in an electrostatically actuated microswitch. Sens. Actuators A Phys. 2001, 93, 19-26. [CrossRef]

5. Pal, J.; Zhu, Y.; Lu, J.-W.; Dao, D.; Khan, F. RF MEMS switches for smart antennas. Microsyst. Technol. 2015, 21, 487-495. [CrossRef]

6. Shi, W.; Tien, N.; Li, Z. A highly reliable lateral MEMS switch utilizing undoped polysilicon as isolation material. J. Microelectromech. Syst. 2007, 16, 1173-1184.

7. Zhu, Y.; Moheimani, S.O.R.; Yuce, M. Bidirectional Electrothermal Actuator With Z-Shaped Beams. IEEE Sens. J. 2012, 12, 2508-2509. [CrossRef]

8. Pal, J.; Zhu, Y.; Lu, J.; Dao, D.V.; Pal, J. A novel electrothermally actuated RF MEMS switch for wireless applications. In Proceedings of the 2013 IEEE 8th Conference on Industrial Electronics and Applications (ICIEA), Melbourne, Australia, 19-21 June 2013; pp. 1594-1598.

9. Pal, J.; Zhu, Y.; Lu, J.; Dao, D.; Khan, F. High Power and Reliable SPST/SP3T RF MEMS Switches for Wireless Applications. IEEE Electron Device Lett. 2016, 37, 1219-1222. [CrossRef]

10. Sharma, K.; Karmakar, A.; Prakash, K.; Chauhan, A.; Bansal, S.; Hooda, M.; Kumar, S.; Gupta, N.; Singh, A.K. Design and characterization of $\mathrm{rf}$ mems capacitive shunt switch for $\mathrm{x}, \mathrm{ku}, \mathrm{k}$ and ka band applications. Microelectron. Eng. 2020, 227, 111310. [CrossRef]

11. Bansal, D.; Kumar, A.; Sharma, A.; Kumar, P.; Rangra, K.J. Design of novel compact anti-stiction and low insertion loss RF MEMS switch. Microsyst. Technol. 2014, 20, 337-340. [CrossRef]

12. Muldavin, J.; Rebeiz, G. Inline capacitive and DC-contact MEMS shunt switches. IEEE Microw. Wirel. Compon. Lett. 2001, 11, 334-336. [CrossRef]

13. Barbato, M.; Meneghesso, G. A novel technique to alleviate the stiction phenomenon in radio frequency microelectromechanical switches. IEEE Electron Device Lett. 2015, 36, 177-179. [CrossRef]

14. Huang, Q.A.; Lees, N.K.S. Analysis and design of polysilicon thermal flexure actuator. J. Micromech. Microeng. 1999, 9, 64-70. [CrossRef]

15. Noworolski, J.M.; Klaassen, E.H.; Logan, J.R.; Petersen, K.E.; Maluf, N.I. Process for in-plane and out-of-plane single-crystal-silicon thermal microactuators. Sens. Actuators A Phys. 1996, 55, 65-69. [CrossRef]

16. Sinclair, M.J. A high force low area MEMS thermal actuator. In Proceedings of the IEEE Inter Society Conference on Thermal Phenomena, Las Vegas, NV, USA, 23-26 May 2000; pp. 127-132.

17. Madou, M. Fundamentals of Microfabrication; CRC Press: Boca Raton, FL, USA, 2000; pp. 406-426.

18. Robert, P.; Saias, D.; Billard, C.; Boret, S.; Sillon, N.; Maeder-Pachurka, C.; Charvet, P.L.; Bouche, G.; Anceyy, P.; Berruyer, P. Integrated RF-MEMS switch based on a combination of thermal and electrostatic actuation. IEEE Transducers Dig. 2003, 2, 1714-1717.

19. Mahameed, R.; Rebeiz, G. A High-Power Temperature-Stable Electrostatic RF MEMS Capacitive Switch Based on a Thermal Buckle-Beam Design. J. Microelectromech. Syst. 2010, 19, 816-826. [CrossRef]

20. Lee, C.-I.; Ko, C.-H.; Huang, T.-C. Design of Multi-actuation RF MEMS Switch Using CMOS Process. In Proceedings of the 2008 3rd International Microsystems, Packaging, Assembly \& Circuits Technology Conference, Taipei, Taiwan, 22-24 October 2008; pp. 141-144.

21. Becker, M.; Benecke, W.; Hannemann, B.; Henning, T. Electrostatic beam actuator for switching applications fabricated by Ni-microelectroplating and thermal postprocessing. Micromach. Microfabr. 2003, 4981, 71-82.

22. Cho, I.J.; Yoon, E. Design and fabrication of a single membrane push-pull SPDT RF MEMS switch operated by electromagnetic actuation and electrostatic hold. J. Micromech. Microeng. 2010, 20, 035028. [CrossRef]

23. Cao, A.; Kim, J.; Lin, L. Bi-directional electrothermal electromagnetic actuators. J. Micromech. Microeng. 2007, 17, 975-982. [CrossRef]

24. Miller, K.; Cowen, A.; Hames, G.; Hardy, B. SOIMUMPS Design Handbook, Revision 4; MEMSCAP Inc.: Durham, NC, USA, 2005.

25. Sterner, M.; Roxhed, N.; Stemme, G.; Oberhammer, J. Static zero power- consumption coplanar waveguide embedded DC-toRF metalcontact MEMS switches in two-port and three-port configuration. IEEE Trans. Electron Devices 2010, 57, 1659-1669. [CrossRef]

26. Liu, A.Q.; Tang, M.; Agarwal, A.; Alphones, A. Low loss lateral micromachined switches for high frequency applications. J. Micromech. Microeng. 2005, 15, 157-167. [CrossRef]

27. Park, J.; Shim, E.S.; Choi, W.; Kim, Y.; Kwon, Y.; Cho, D.I. A non-contact-type RF MEMS switch for 24-GHz radar applications. J. Microelectromech. Syst. 2009, 18, 163-173. [CrossRef]

28. Cao, A.; Yuen, P.; Lin, L. Micro-relays with bi-directional electrothermal electromagnetic actuators and liquid metal wetted contacts. J. Microelectromech. Syst. 2007, 16, 700-708. [CrossRef]

29. Patel, C.D.; Rebeiz, G.M. A High-Reliability High-Linearity High-Power RF MEMS Metal-Contact Switch for DC-40-GHz Applications. IEEE Trans. Microw. Theory Tech. 2012, 60, 3096-3112. [CrossRef]

30. Czaplewski, D.A.; Nordquist, C.D.; Dyck, C.W.; Patrizi, G.A.; Kraus, G.M.; Cowan, W.D. Lifetime limitations of ohmic, contacting RF MEMS switches with Au, Pt, and Ir contact materials due to accumulation of 'friction polymer' on the contacts. J. Micromech. Microeng. 2012, 22, 105005. [CrossRef]

31. Czaplewski, D.A.; Nordquist, C.D.; Patrizi, G.A.; Kraus, G.M.; Cowan, W.D. RF MEMS switches with RuO -Au contacts cycled to 10 billion cycles. J. Microelectromech. Syst. 2013, 22, 655-661. [CrossRef] 
32. Zareie, H.; Rebeiz, G.M. Compact High-Power SPST and SP4T RF MEMS Metal-Contact Switches. IEEE Trans. Microw. Theory Tech. 2014, 62, 297-305. [CrossRef]

33. Stefanini, R.; Chatras, M.; Blondy, P.; Rebeiz, G.M. Miniature MEMS Switches for RF Applications. J. Microelectromech. Syst. 2011, 20, 1324-1335. [CrossRef]

34. Lakshminarayanan, B.; Mercier, D.; Rebeiz, G. High-Reliability Miniature RF-MEMS Switched Capacitors. IEEE Trans. Microw. Theory Tech. 2008, 56, 971-981. [CrossRef] 